\title{
Hot Tensile and Fracture Behavior of 35CrMo Steel at Elevated Temperature and Strain Rate
}

\author{
Zhengbing Xiao ${ }^{1, *}$, Yuanchun Huang ${ }^{1,2}$, Hui Liu ${ }^{2}$ and Sanxing Wang ${ }^{1}$ \\ 1 School of Mechanical and Electrical Engineering, Central South University, Changsha 410083, China; \\ science@csu.edu.cn (Y.H.); wangsanxing@csu.edu.cn (S.W.) \\ 2 Light Alloy Research Institute, Central South University, Changsha 410012, China; liuhui2015@csu.edu.cn \\ * Correspondence: xiaozb@csu.edu.cn; Tel.: +86-731-8887-6315
}

Academic Editor: Hugo F. Lopez

Received: 29 June 2016; Accepted: 29 August 2016; Published: 31 August 2016

\begin{abstract}
To better understand the tensile deformation and fracture behavior of 35CrMo steel during hot processing, uniaxial tensile tests at elevated temperatures and strain rates were performed. Effects of deformation condition on the flow behavior, strain rate sensitivity, microstructure transformation, and fracture characteristic were characterized and discussed. The results indicated that the flow stress was sensitive to the deformation condition, and fracture occurs immediately after the peak stress level is reached, especially when the temperature is low or the strain rate is high. The strain rate sensitivity increases with the deformation temperature, which indicates that formability could improve at high temperatures. Photographs showing both the fracture surfaces and the matrix near the fracture section indicated the ductile nature of the material. However, the fracture mechanisms varied according to the deformation condition, which influences the dynamic recrystallization (DRX) condition, and the DRX was accompanied by the formation of voids. For samples deformed at high temperatures or low strain rates, coalescence of numerous voids formed in the recrystallized grains is responsible for fracture, while at high strain rates or low temperatures, the grains rupture mainly by splitting because of cracks formed around the inclusions.
\end{abstract}

Keywords: hot tensile; 35CrMo; fracture; deformation behavior

\section{Introduction}

Because of its good balance between strength, ductility, and wear resistance, 35CrMo steel is widely used to fabricate critical parts working in harsh environments, e.g., transmission shafts, gears, and bearings that are usually subjected to high cycles of stress, large loads, and corrosive surroundings; further, the mechanical properties of the alloy require the full extent, and defects such as cracks and holes formed during hot working are detrimental [1]. To avoid defects, a good understanding of the cavitation behavior and the fracture mechanism for the $35 \mathrm{CrMo}$ steel is of paramount importance [2].

Uniaxial tensile tests at different deformation conditions were used to a great extent to optimize the hot deformation behavior of the alloys, with the aim to prevent the cavitation and fracture of the parts processed [3]. Specifically, the uniaxial tensile test can be used to not only determine the strength of the alloy but also obtain the ductility data, which is valuable to evaluate various factors affecting the formability and performance under complex deformation conditions [4]. Using hot tensile testing, the fracture mechanism and hot deformation behavior of Incoloy 901 was studied by Shore et al., and they optimized the deformation parameters to minimize the risk of fracture; they attributed the observed fracture to the grain boundary decohesion [5]. The fracture morphology and other properties of AZ31 magnesium alloy were investigated by Jiao Deng et al. by performing hot tensile tests; the results indicated that the fracture mechanism changes with the deformation conditions and that a suitable amount of the liquid phase should preferably be present between the grain boundaries for 
ductility [6]. In 2011, Bai et al. studied the influence of carbides and grain boundary conditions on the fracture behavior of a Ni-Cr-W-based superalloy and concluded that the strength of the grain boundary was weakened by the lamellar M23C6 carbides with a 1-3- $\mu$ m width [7]. A modified Oyane-Sato fracture criterion was proposed and applied to the cross wedge rolling process of the AA6082-T6 bars by Novella et al. who performed hot tensile tests at elevated temperatures [8]. The effects of the microstructure on hot tensile deformation behavior of 7075 alloy was evaluated by Wang and his co-workers [9]. Further, a similar dependence of the fracture behavior on the deformation conditions was reported for the IMI834 titanium alloy [10], TA15 Ti alloy [11], Mg-9.3Li-1.79Al-1.61Zn alloy [12], and other alloys $[13,14]$, all of which indicate that hot tensile tests are a powerful tool to investigate the fracture and high-temperature behavior of alloys. However, there is little information about the fracture behavior for 35CrMo steel, and most studies to date have focused on the surface treatment and related performance [15-19]. Therefore, the fundamental cavitation and fracture behavior of 35CrMo need further investigation.

Hence, in this paper, the effect of strain rate and temperature on the fracture performance of hot-rolled 35CrMo steel is investigated systematically. Efforts were also made to analyze the relationships between the fracture morphology and the DRX.

\section{Materials and Methods}

The experimental material was a hot-rolled 35CrMo steel bar with a diameter of $12 \mathrm{~mm}$. Its chemical composition (wt. \%) was as follows: C: 0.344; Cr: 0.95; Mo: 0.19; Mn: 0.56; Si: 0.21; P: 0.018; S: 0.005; Al: 0.0032; Fe: Balance. The shape and size of the samples machined from the bars are shown in Figure 1. Hot tensile tests were carried out at temperatures of $850{ }^{\circ} \mathrm{C}, 950{ }^{\circ} \mathrm{C}, 1050{ }^{\circ} \mathrm{C}$, and $1150{ }^{\circ} \mathrm{C}$ and strain rates of $0.01 \mathrm{~s}^{-1}, 0.1 \mathrm{~s}^{-1}, 1 \mathrm{~s}^{-1}$, and $10 \mathrm{~s}^{-1}$, and the samples were hot stretched to break using a Gleeble 3500 machine (DSI ${ }^{\circledR}$, New York, NY, USA). To eliminate the temperature gradient, the samples were heated to $1150{ }^{\circ} \mathrm{C}$ at the rate of $10{ }^{\circ} \mathrm{C} / \mathrm{s}$, and this temperature was maintained for $2 \mathrm{~min}$, after which the samples were cooled to the deformation temperature at the rate of $10^{\circ} \mathrm{C} / \mathrm{s}$ prior to loading. Once the samples were elongated to fracture, liquid nitrogen was used to cool them down to preserve the deformed microstructure.

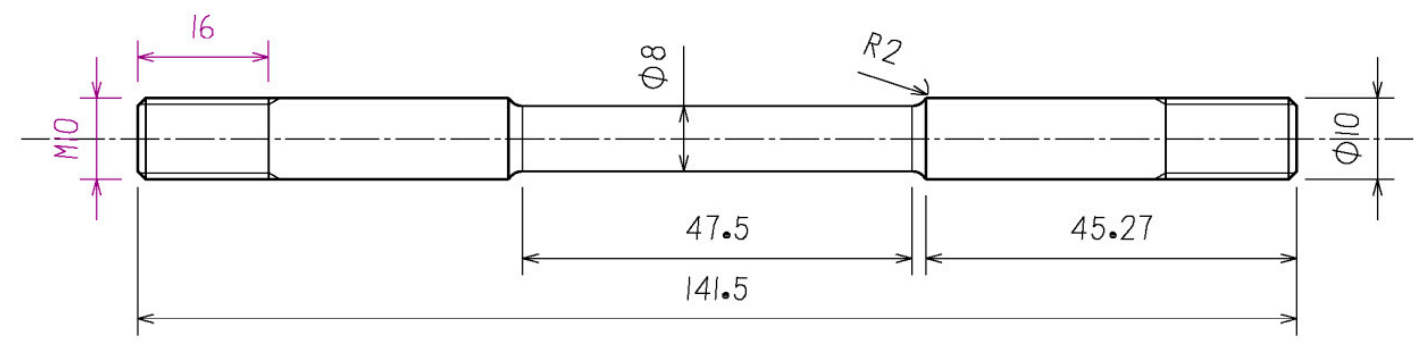

Figure 1. Scheme of the tensile specimen (all dimensions are in $\mathrm{mm}$ ).

After the uniaxial tensile tests, the fracture surfaces were examined by scanning electron microscopy (SEM, FEI, Hillsboro, OR, USA). Then, the samples were sliced along the longitudinal direction, mechanically polished, and chemically etched with a solution $\left(2.5 \mathrm{~g}\right.$ picric acid, $50 \mathrm{~mL} \mathrm{H}_{2} \mathrm{O}$, $1 \mathrm{~mL} \mathrm{HCl}$, and $2 \mathrm{~g}$ detergent) at $60-80{ }^{\circ} \mathrm{C}$ for $4-10 \mathrm{~min}$ to carry out both optical microscopy (OM, Olympus, Tokyo, Japan) and SEM observations.

\section{Results and Discussion}

\subsection{Hot Tensile Behavior}

Figure 2 shows flow curves of the specimens tested under a strain rate of $0.1 \mathrm{~s}^{-1}$ and the temperature of $850{ }^{\circ} \mathrm{C}$ after the elimination of effects due to the stress triaxiality according to the method proposed by Williams [20]. As shown, the flow stresses are significantly affected by the strain 
rate and temperature. The flow stress exhibits work hardening at the initial deformation stage, and then the strength decreases quickly after the peak stress to fracture. Additionally, the flow stress varies proportionally with the strain rate but is inversely proportional to the deformation temperature. Further, the fracture strain tends to increase with increasing strain rate but decreasing deformation temperature. With decreasing strain rate, the time for the energy accumulation was prolonged, while the mobility of the grain boundaries and atoms increased with the temperature; this makes annihilation of dislocations, nucleations, and DRX growth much easier and thus results in a decrease in the flow stress [21].

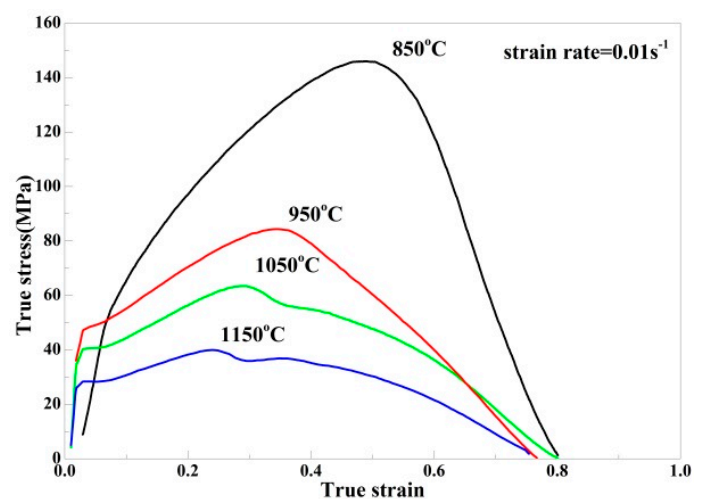

(a)

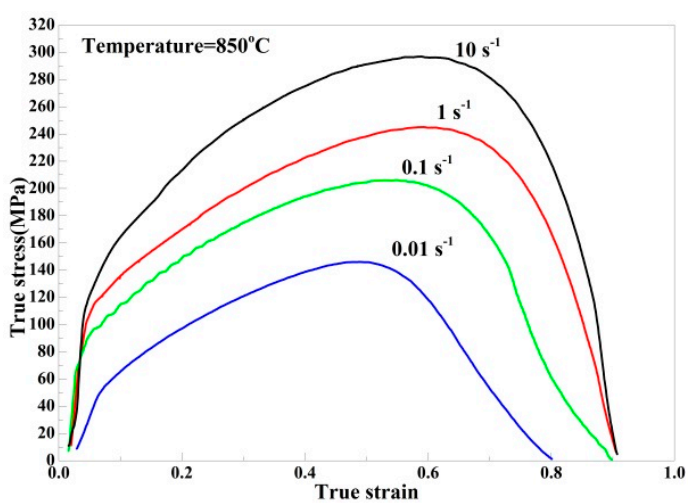

(b)

Figure 2. Typical flow stress curves of the studied 35CrMo steel under different conditions. (a) At the strain rate of $0.01 \mathrm{~s}^{-1} ;(\mathbf{b})$ at the temperature of $850{ }^{\circ} \mathrm{C}$.

As revealed by Hutchinson et al. [22], the strain rate sensitivity can be used to characterize the strain location and necking in the hot tensile deformation of alloys. The relationships between the strain rate sensitivity coefficient $(m)$ and temperature for the 35CrMo steel studied is shown in Figure 3. The figure shows that $m$ increases with the temperature, which indicates the increase in the necking transferability, diffusion ability, and workability. Further, with increasing temperature, $1 / m$ becomes closer to 5. This means that dislocation slip and climb are responsible for the deformation; moreover, these are the main deformation mechanisms of materials with big grains [6], including 35CrMo steel (as shown in Figure 3c).

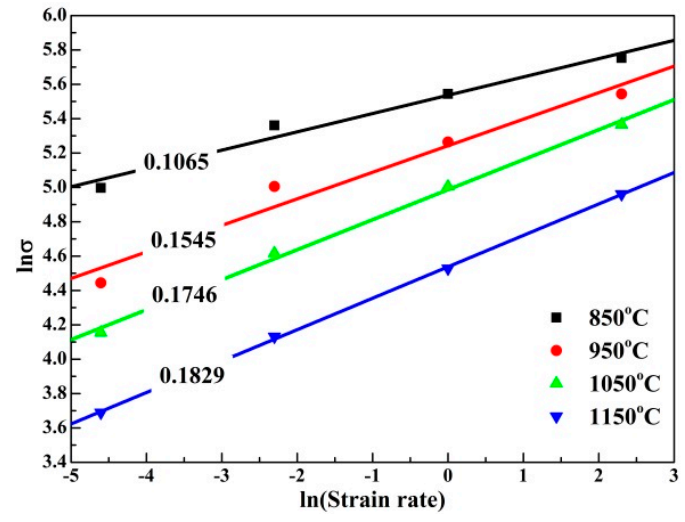

(a)

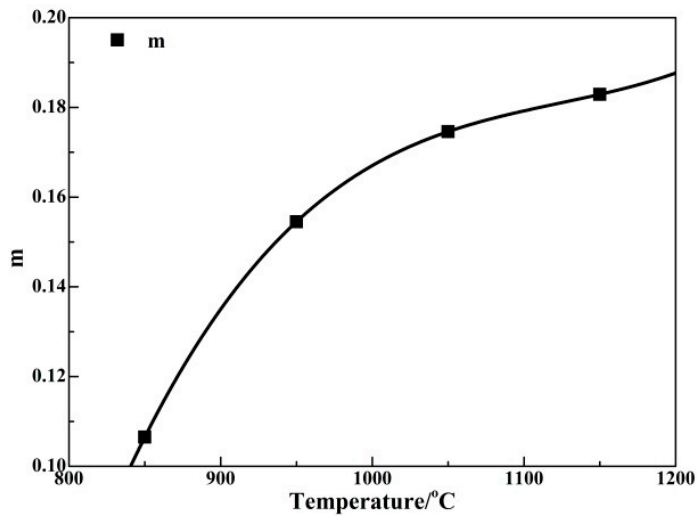

(b)

Figure 3. Cont. 


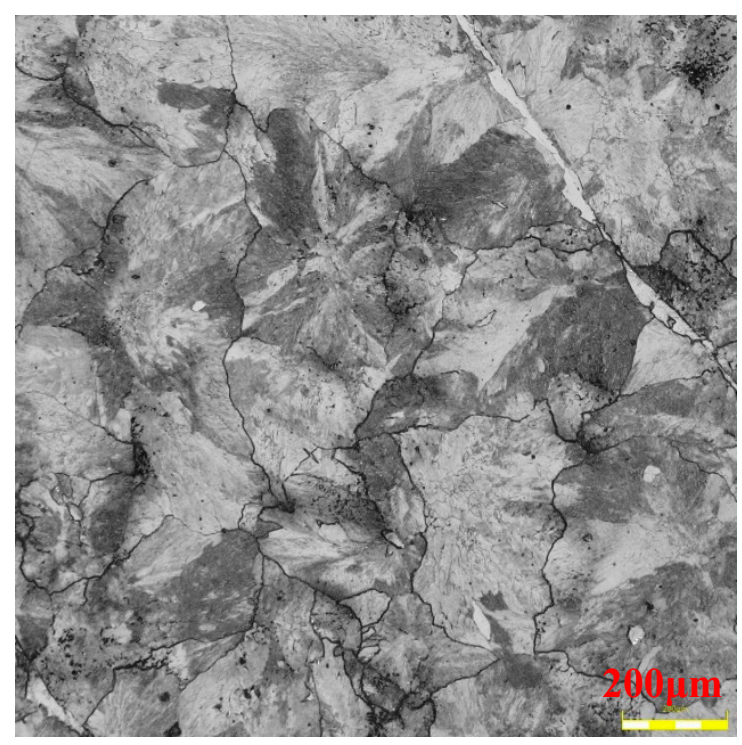

(c)

Figure 3. Influence of temperature on the strain rate sensitivity value $m$ (a) and its relationship with temperature (b), and the microstructure as received (c).

\subsection{Fracture Morphology Analysis}

The fracture morphologies of the samples deformed at temperatures from $850{ }^{\circ} \mathrm{C}$ to $1150{ }^{\circ} \mathrm{C}$ and at a strain rate of $10 \mathrm{~s}^{-1}$ are presented in Figure 4. All the fracture surfaces are covered with dimples, which indicate the ductile nature of the material at these deformation conditions. With rising deformation temperature, the reduction in area and size of the dimples becomes bigger and the number of dimples on the fracture surfaces decreases, which is extremely obvious when the temperature goes up from $850{ }^{\circ} \mathrm{C}$ to $1150{ }^{\circ} \mathrm{C}$. Further, tenacity nests are presented for all the fracture surfaces, which were originated from the form of dislocation creep caused by the atom diffusion. However, with increasing temperature, the number of blade-type edges decreases, as can be seen from Figure $4 \mathrm{~h}, \mathrm{k}$; further, serpentine sliding on the wall of the dimples also becomes more obvious (Figure 4c,f).

Figure 4a illustrates the fracture surface for elongation at $850{ }^{\circ} \mathrm{C} / 10 \mathrm{~s}^{-1}$ : the surface is covered with a large number of tearing edges and small dimples. It can be deduced from Figure $4 a$ that occurrence of internal necking is difficult in the case of the studied $35 \mathrm{CrMo}$ steel at $850{ }^{\circ} \mathrm{C}$. In fact, more macroscopic dimples were generated during the deformation, rather than the coalescence of the dimples formed like the sample deformed at $1150{ }^{\circ} \mathrm{C}$ as shown in Figure $4 \mathrm{j}$, the fracture of which can be attributed to the combination of the micro voids. Additionally, inclusions can be found at the bottom of the dimples in Figure $4 \mathrm{a}, \mathrm{e}$, but not for the samples deformed at $1050{ }^{\circ} \mathrm{C}$ and $1150{ }^{\circ} \mathrm{C}$. The pile up of dislocations around the inclusions can be eliminated for the increased mobility of atoms and grain boundaries at high temperatures. Further, the plasticity of the inclusions improved, and it can be elongated in accordance with the matrix without separating from the matrix.

Figure 5 shows the fracture morphology of the samples tested at the deformation temperature of $850{ }^{\circ} \mathrm{C}$ and strain rate of $0.01 \mathrm{~s}^{-1}, 0.1 \mathrm{~s}^{-1}$, and $1 \mathrm{~s}^{-1}$. As can be seen from the figures, with increasing strain rate, the area reduction and size of the dimples decreased, but the number of the dimples and blade-type edges increased. On the other hand, the number of blade-type edges decreased with decreasing deformation temperature, which indicates that occurrence of internal necking becomes increasingly difficult with the increased strain rate. From the high-resolution figures, as in Figure $5 f$, serpentine sliding and tenacity nests are found on walls of the dimples (also in Figure 4c). Tenacity nests were formed as a result of the dislocation creep, and the serpentine sliding resulted when the principle stress was perpendicular to the dimple surface [6]. 


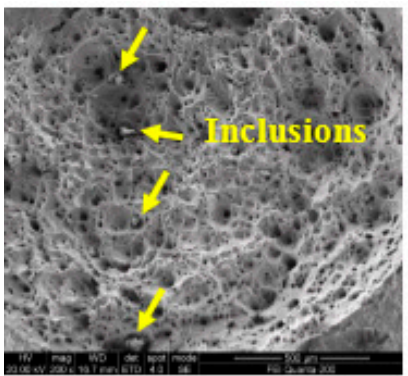

(a)

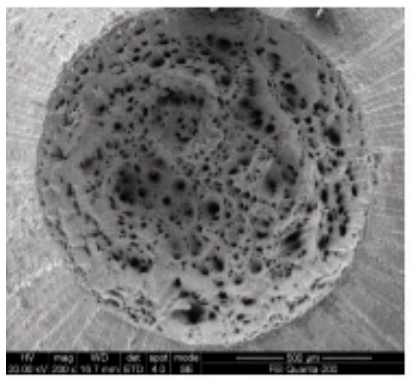

(d)

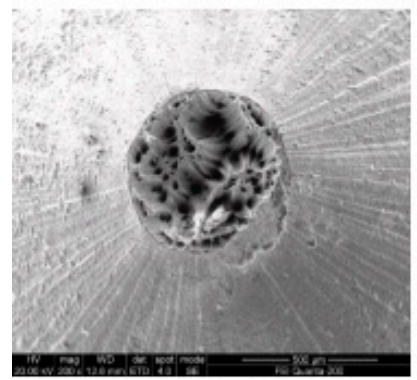

(g)

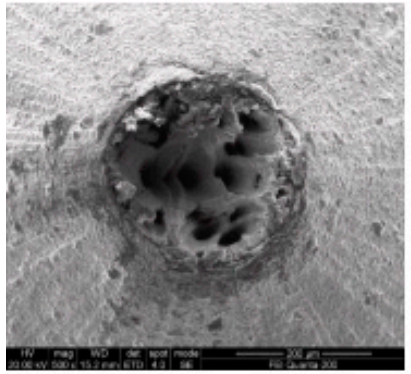

(j)

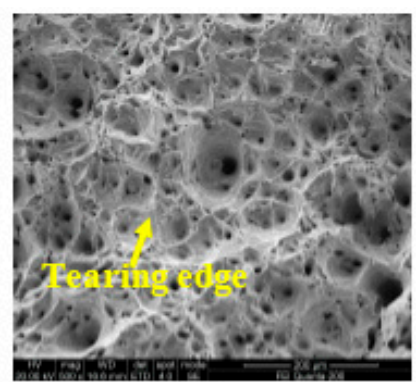

(b)

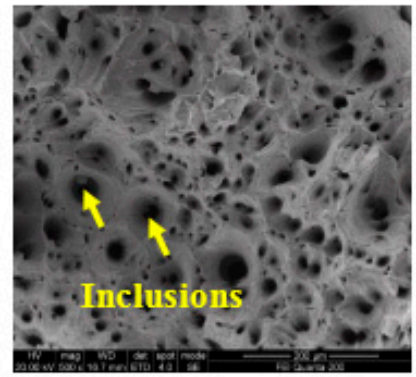

(e)

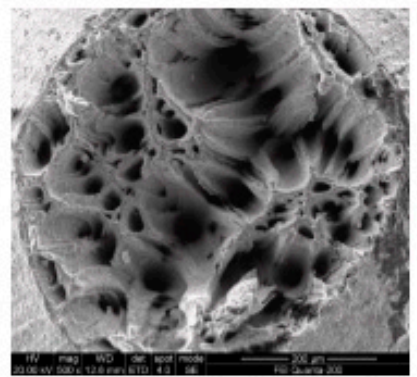

(h)

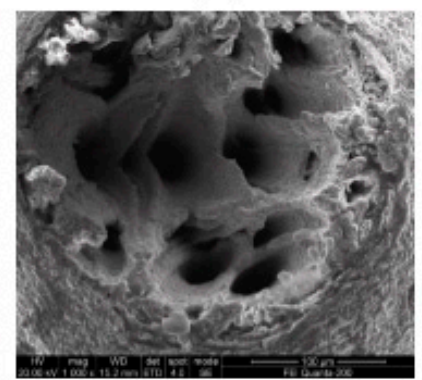

(k)

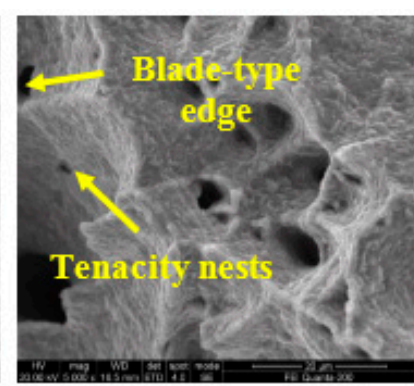

(c)

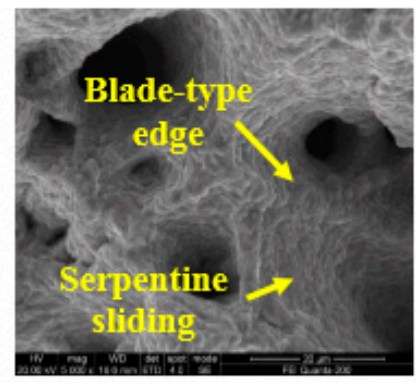

(f)

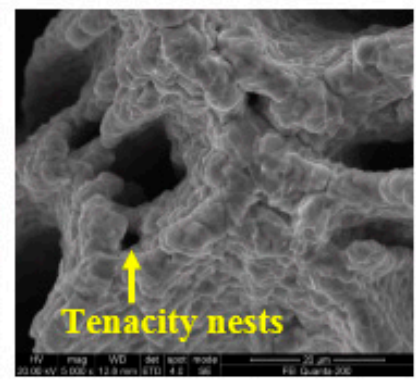

(i)

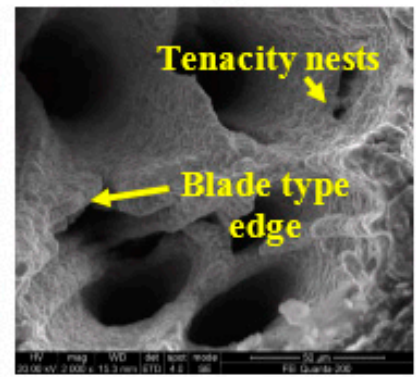

(1)

Figure 4. The fracture morphology at a strain rate of $10 \mathrm{~s}^{-1}$ and temperature of $(\mathbf{a}, \mathbf{b}, \mathbf{c}) 850{ }^{\circ} \mathrm{C}$; $(\mathbf{d}, \mathbf{e}, \mathbf{f}) 950{ }^{\circ} \mathrm{C} ;(\mathbf{g}, \mathbf{h}, \mathbf{i}) 1050{ }^{\circ} \mathrm{C}$; and $(\mathbf{j}, \mathbf{k}, \mathbf{l}) 1150^{\circ} \mathrm{C}$. 


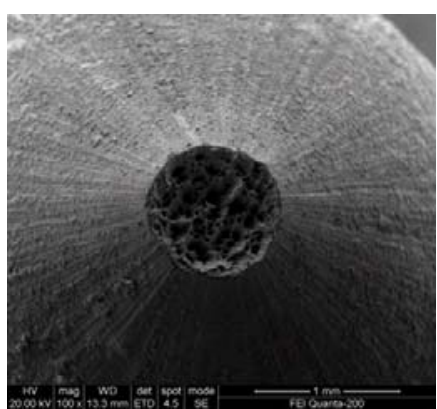

(a)

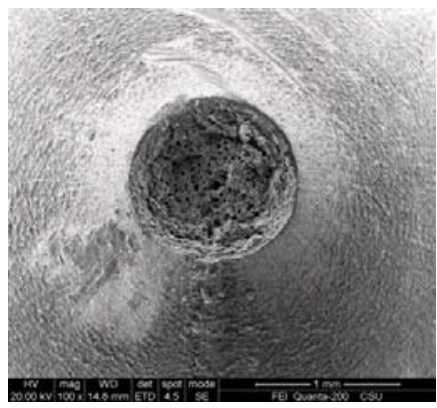

(d)

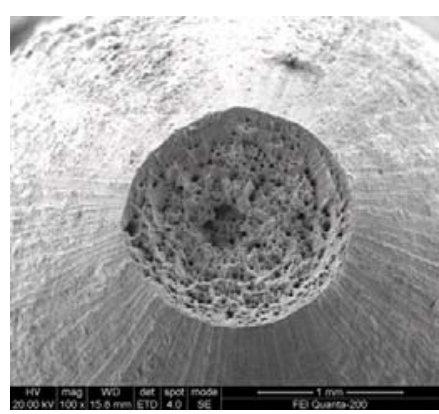

(g)

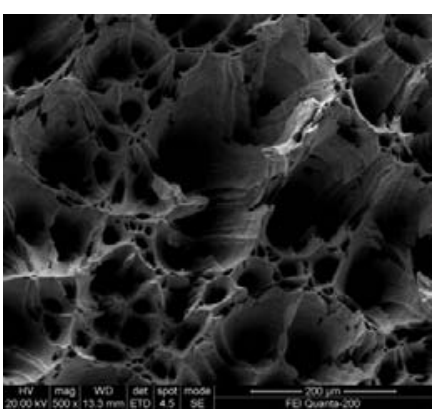

(b)

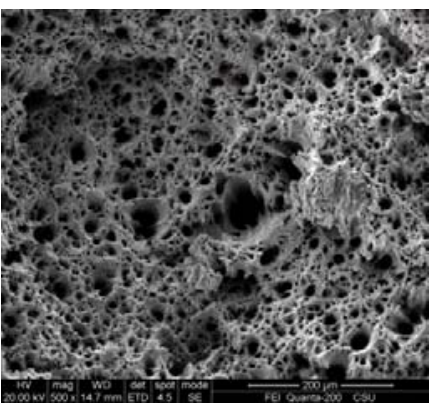

(e)

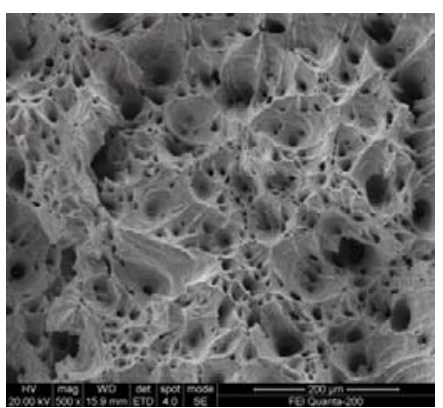

(h)

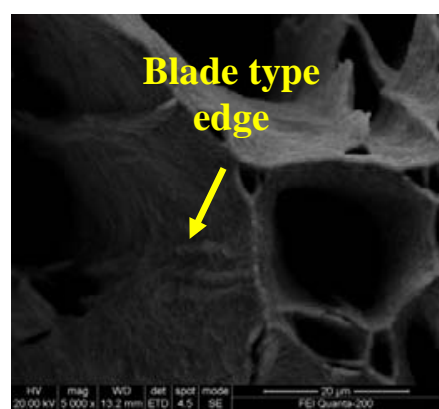

(c)

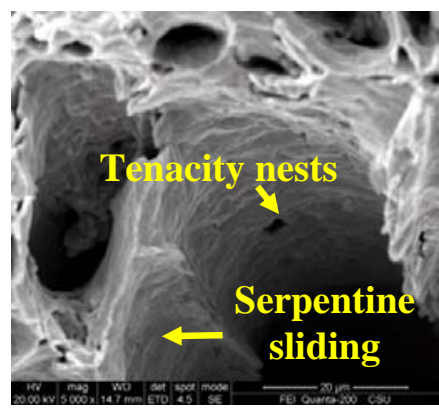

$(\mathbf{f})$

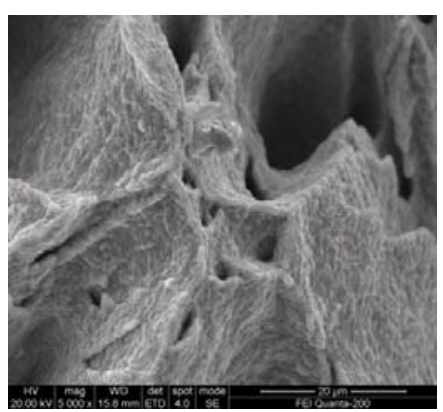

(i)

Figure 5. The fracture morphology under $850{ }^{\circ} \mathrm{C}$ at a strain rate of $(\mathbf{a}, \mathbf{b}, \mathbf{c}) 0.01 \mathrm{~s}^{-1}$; (d,e,f) $0.1 \mathrm{~s}^{-1}$; $(\mathbf{g}, \mathbf{h}, \mathbf{i}) 1 \mathrm{~s}^{-1}$.

\subsection{Microstructure Analysis}

The size of the dimples on the fracture surface is governed by the number and distribution of microvoids that are nucleated. When the nucleation sites are widely spaced and few, the cavities grow to a large size directly before coalescing, which result in the fracture surface having large dimples. Small dimples are formed when numerous nucleating sites are activated and adjacent microvoids coalesce, and rupture occurs before they have an opportunity to grow to a larger size.

To reveal the formation and expansion mechanism of the cavities during hot tensile testing, a better understand of the microstructural evolution is important. Figure $6 \mathrm{a}-\mathrm{f}$ shows the representative microstructure for the samples tested at the temperatures of $850{ }^{\circ} \mathrm{C}$ and $1050{ }^{\circ} \mathrm{C}$ under the strain rate of $0.01 \mathrm{~s}^{-1}$ and $10 \mathrm{~s}^{-1}$; these are near the fracture surface, and the grain structure of the sample before elongation is illustrated in Figure 3c. According to Figure 6, after the tensile tests, DRX is observed, as-received big grains were crystallized into equiaxed grains, and the recrystallized grain size reduces with increasing strain rate and decreasing temperature. This phenomenon was also observed and well explained from the viewpoint of energy accumulation and grain boundaries and atom mobility in other alloys [23,24]. 


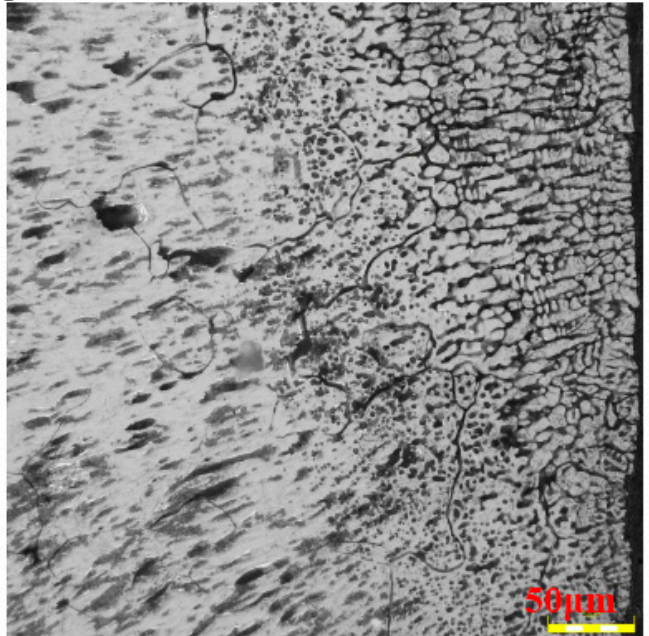

(a)

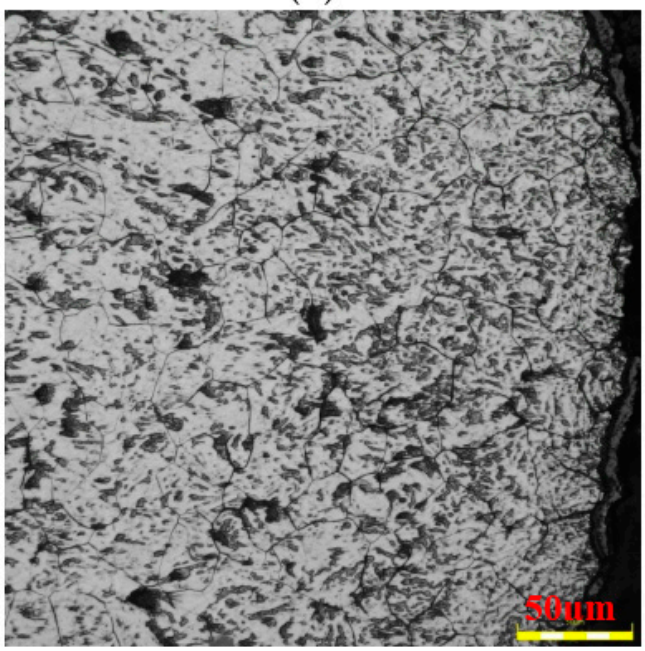

(c)

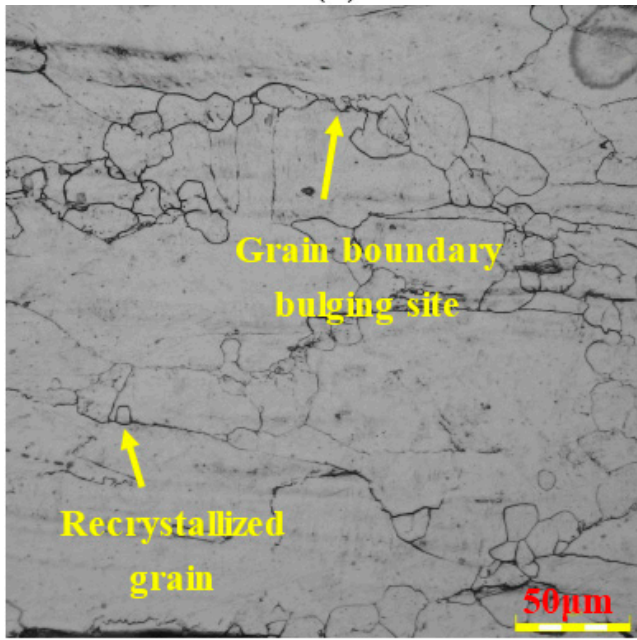

(e)

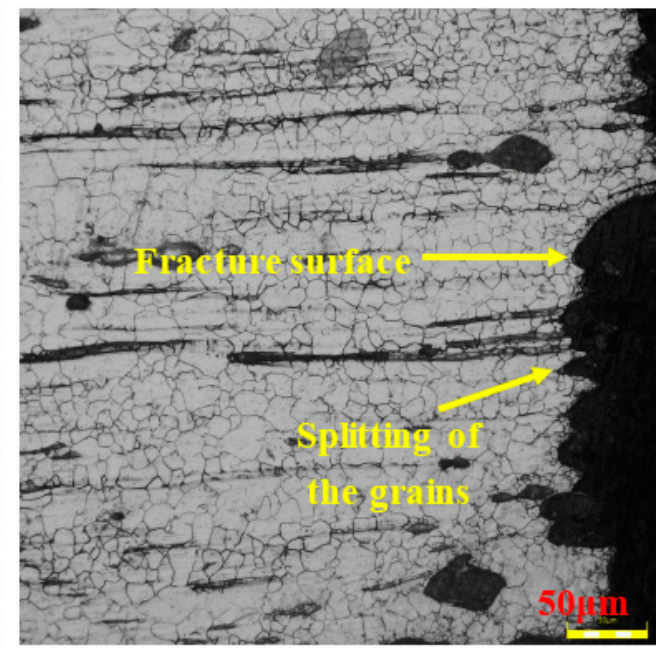

(b)

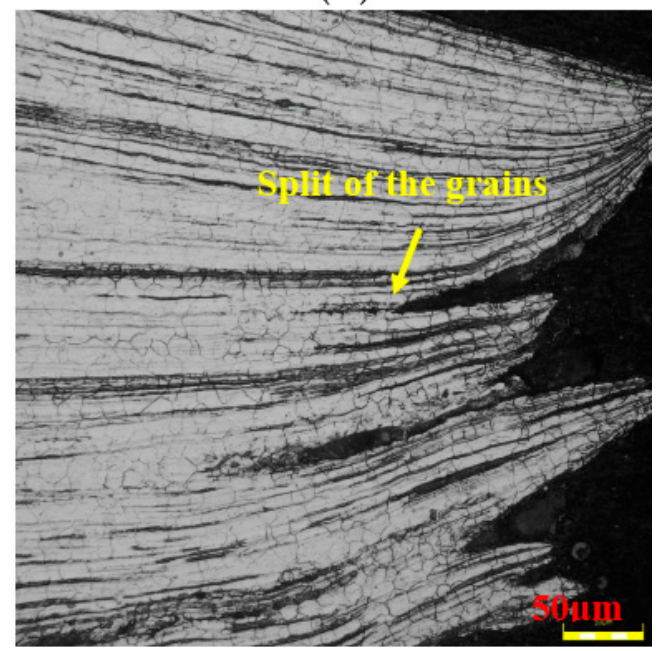

(d)

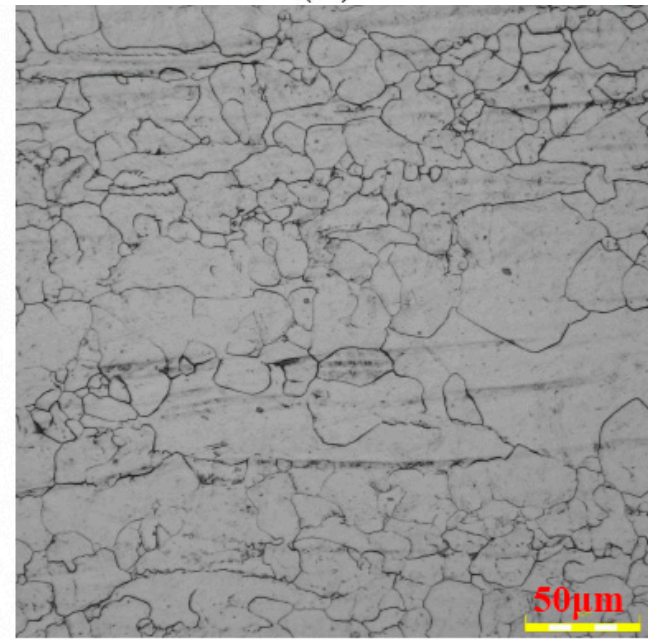

(f)

Figure 6. Microstructures near the fracture face of the samples tested at (a) $850{ }^{\circ} \mathrm{C} / 0.01 \mathrm{~s}^{-1}$, (b) $850{ }^{\circ} \mathrm{C} / 10 \mathrm{~s}^{-1}$, (c) $1050{ }^{\circ} \mathrm{C} / 0.01 \mathrm{~s}^{-1}$, and (d) $1050{ }^{\circ} \mathrm{C} / 10 \mathrm{~s}^{-1}$ and the microstructure for and (e,f) $850^{\circ} \mathrm{C} / 10 \mathrm{~s}^{-1}$ (around $5 \mathrm{~mm}$ from the fracture surface). 
Figure 6e represents the microstructure at the location $5 \mathrm{~mm}$ from the fracture surface for the sample deformed at $850{ }^{\circ} \mathrm{C} / 10 \mathrm{~s}^{-1}$ : it is partially recrystallized, and small grains can be found at the bulging site between the grains and grain boundary bulging is the major mechanism of the nucleation during DRX. Figure 6f presents a location much closer to the fracture surface, with much strain and full DRX but without cavities. It can be concluded that DRX occurred before the formation of cavities. Additionally, as can be seen from Figure 6, cavities in the matrix deformed at the strain rate of $10 \mathrm{~s}^{-1}$ are much larger than those in the matrix deformed at $0.01 \mathrm{~s}^{-1}$, both at $850{ }^{\circ} \mathrm{C}$ and $1050{ }^{\circ} \mathrm{C}$. However, cavities are fewer in number and grain splitting is clear at high strain rates, especially for the one elongated at $1050{ }^{\circ} \mathrm{C}$. Apparently, the DRX has an important role in controlling the cavitation and fracture behavior, and the number of voids in the matrix increased with the grain size.

The SEM image for the sample elongated at $850{ }^{\circ} \mathrm{C} / 0.01 \mathrm{~s}^{-1}$ near the fracture surface is illustrated in Figure 7a: The matrix can be divided into three different zones roughly as marked. Zone I is occupied by columnar grain-like microstructures, Zone II has numerous holes, and Zone III seems to be unaffected. High-magnification image of Zones I and II are presented in Figure 7b, and grains in Zone I are divided into tiny isolated areas where voids join, with the boundaries parallel to the elongation direction. However, it should be noted that the voids are not propagated along the grain boundaries, and the joining of the microvoids in the grains was responsible for the rupture. Additionally, the true strain increases from Zone III to Zone I, which indicated the rupture that the sample experiences is due to the process of massive nucleation, growth, and converging of the microvoids.

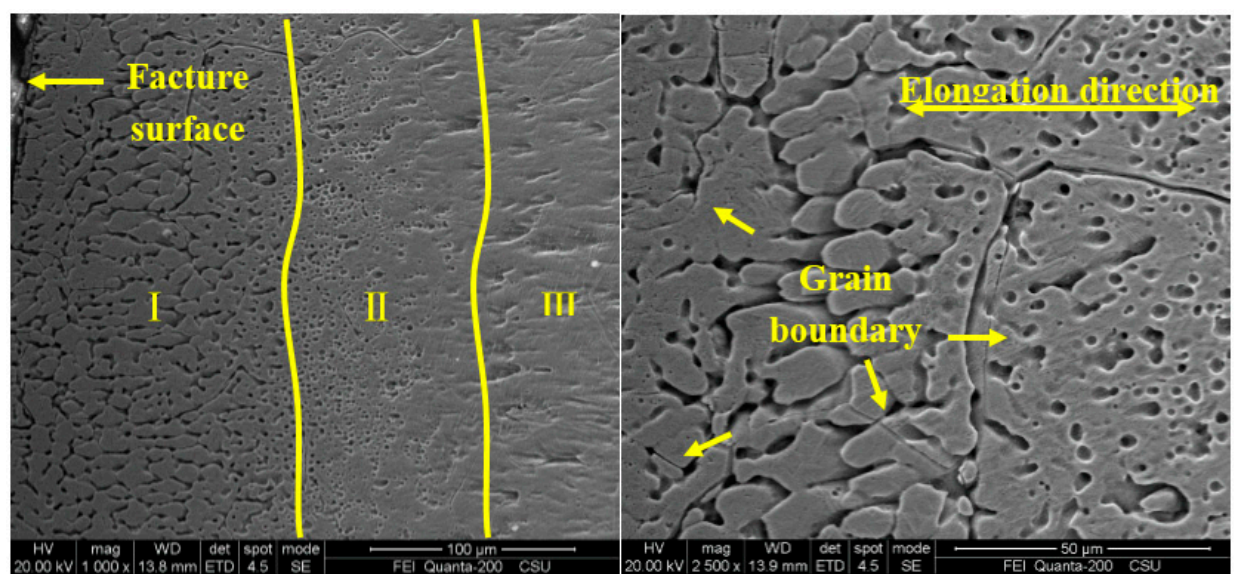

(a)

(b)

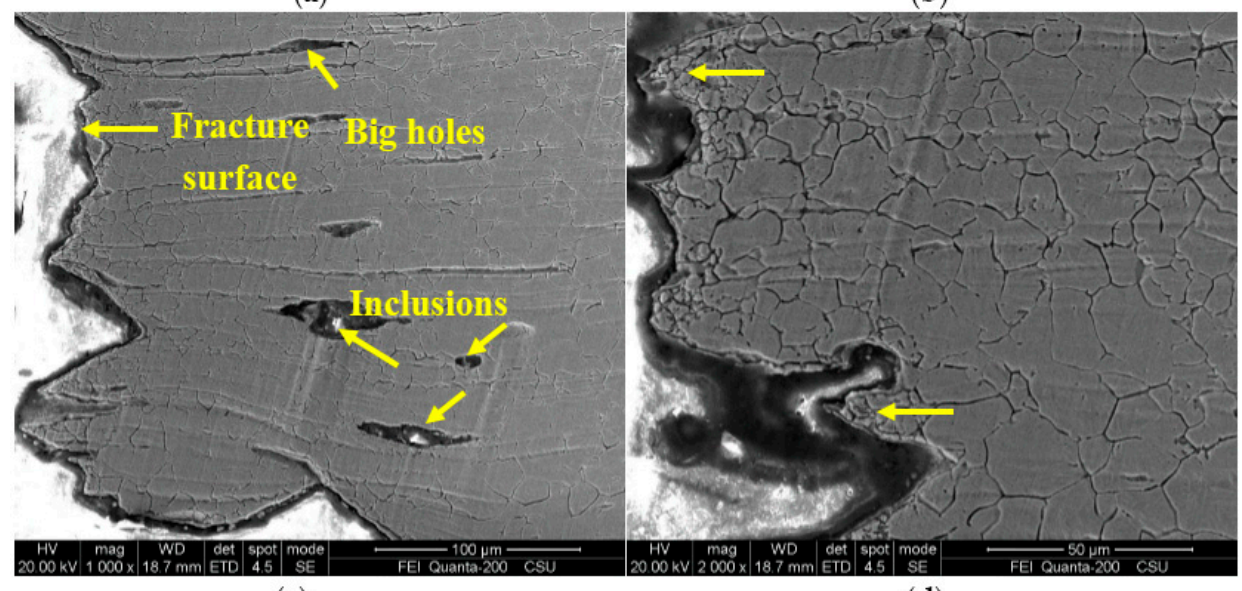

(c)

(d)

Figure 7. Microstructures near the fracture face of the samples tested at $(\mathbf{a}, \mathbf{b}) 850{ }^{\circ} \mathrm{C} / 0.01 \mathrm{~s}^{-1}$ and (c,d) $850{ }^{\circ} \mathrm{C} / 10 \mathrm{~s}^{-1}$. 
The SEM image of microstructure of the samples deformed at $850{ }^{\circ} \mathrm{C} / 10 \mathrm{~s}^{-1}$ is illustrated in Figure $7 \mathrm{c}$ : it is quite different from that for the sample elongated at the strain rate of $0.01 \mathrm{~s}^{-1}$. From the image, the process of microvoid formation and converging is not obvious, but big voids are found, as depicted in Figure 7c. With increasing strain rate, coalescence and converging of several voids around the inclusions occur, which is the main reason for fracture. Efficiency decreased with the enlargement of the cavities, and then splitting occurs with the rupture of the grains, as shown in Figure $7 \mathrm{~d}$.

It is well known that nucleation sites for the microvoids originate from the dislocation movement along the slip plane in the hot stretching process. When the dislocation cannot overcome obstacles, there will be a dislocation pile-up, and microvoids are created when external stress exceeds the nucleation threshold of the material [25]. Additionally, as pointed out by researchers [26-28], the true strain needed to complete the DRX decreases for the increased deformation temperature and decreased strain rate, which indicated that the initiation of the cavitation for those tested at low temperatures or high strain rates was delayed, and the formation of the voids occurred earlier in the matrix for those with high temperatures or low strain rates.

For those tested at a high temperature, atoms and grain boundaries mobility was promoted, the dislocations around micro-inclusions were eliminated, resulting in the dynamic recovery and DRX, or were pushed to the grain boundaries. Further, when the strain rate is low, time for the dynamic recrystallized grains to grow is sufficient, as presented in Figures $6 \mathrm{a}$ and $7 \mathrm{~b}$, and the grain size increases. However, dislocations will be generated in the newly formed dynamic recrystallized grains for the continued deformation, which is beneficial for the cavitation and coalescence of the voids produced in the matrix. With a high density of microvoids and the increased mobility of the matrix, coalescence of the voids results in fracture over the surface with connected big dimples. However, the annihilation of the dislocations was also promoted by the high temperature and low strain rate, leading to the damage tolerance of the samples tested at those conditions that were increased, and the resistance stresses at these conditions exhibit a gradual decrease beyond the peak stress, which is obvious when the strain rate is $0.01 \mathrm{~s}^{-1}$, as illustrated in Figure 2.

With decreased temperature and increased strain rate, more plastic deformation is needed to complete DRX, and the energy left for cavitation decreases. During the tensile test, high-dislocation-density locations are more common around the piled-up inclusions, ideal for the nucleation of the voids. However, coalescence of voids must overcome obstacles like neighboring dislocations and grain boundaries between them. As shown in Figures 6 and 7, grains were refined and the number of the voids were reduced, for the decreased temperature and increased strain rate, energy needed for the voids to cut through the matrix and grain boundaries becomes quite high, making the coalesce of the voids more difficult, and thus the fracture surface covered with numerous small dimples. Additionally, the annihilation of the dislocations becomes tougher, because the atom and grain boundary mobility decreases for the decreased temperature and increased strain rate, and a sharp rise in the dislocation density will cause the decreased damage tolerance of the samples to be deformed at these conditions. The samples will quickly lose their efficiency once the voids are formed, the stress will decrease sharply, as shown in Figure 2, and fracture will then occur.

\section{Conclusions}

The hot tensile deformation behaviors of 35CrMo steel were investigated at different temperatures and strain rates, and the effects of deformation conditions on the flow behavior, fracture morphology, and microstructure changes were characterized and discussed. Our conclusions are as follows:

1. The true stress-strain curves indicated that the hot tensile deformation behavior of $35 \mathrm{CrMo}$ is sensitive to the temperature and strain rate, and the resistance stress decreases when the temperature increases or the strain rate decreases. Further, neck transferability and workability of $35 \mathrm{CrMo}$ steel can be improved by increasing the tensile temperature.

2. DRX is accompanied by the formation of cavities, and the cavitations are easier to initiate in the recrystallized grains rather than at the grain boundaries. The grain size reduces for the 
decreased deformation temperature and the increased strain rate, which makes the generation and coalescence of the cavities more difficult, and voids form around the inclusions, leading to the fracture surfaces covered with numerous small dimples. However, for the increased mobility of the atoms and boundaries and prolonged time, void combination is apparently easier under a high temperature and low strain rate, leading to fracture surfaces with a small number of big dimples.

3. The fracture mechanism of 35CrMo steel includes the nucleation, growth, and combination of the microvoids during hot tensile testing. Damage tolerance can be improved with increased deformation temperature and decreased strain rate. To reduce the probability of the formation of cavitation in the matrix, deformation after the completion of DRX for 35CrMo steel should be carefully controlled.

Acknowledgments: This research was supported by National Basic Research Program of China (2014CB046702). Author Contributions: Xiao Zhengbing conceived and designed the experiments; Liu Hui and Wang Sanxing performed the experiments; Xiao Zhengbing analyzed the data; Huang Yuanchun contributed reagents/ materials/analysis tools; Xiao Zhengbing wrote the paper.

Conflicts of Interest: The authors declare no conflicts of interest.

\section{References}

1. Zhang, J.W.; Lu, L.T.; Wu, P.B.; Ma, J.J.; Wang, G.G.; Zhang, W.H. Inclusion size evaluation and fatigue strength analysis of 35CrMo alloy railway axle steel. Mater. Sci. Eng. A 2013, 562, 211-217. [CrossRef]

2. Churyumov, A.Y.; Khomutov, M.G.; Solonin, A.N.; Pozdniakov, A.V.; Churyumova, T.A.; Minyaylo, B.F. Hot deformation behaviour and fracture of $10 \mathrm{CrMoWNb}$ ferritic-martensitic steel. Mater. Des. 2015, 74, 44-54. [CrossRef]

3. Khamei, A.A.; Dehghani, K. Effects of strain rate and temperature on hot tensile deformation of severe plastic deformed 6061 aluminum alloy. Mater. Sci. Eng. A 2015, 627, 1-9. [CrossRef]

4. Sun, C.Y.; Guo, N.; Fu, M.W.; Liu, C. Experimental investigation and modeling of ductile fracture behavior of trip780 steel in hot working conditions. Int. J. Mech. Sci. 2016, 110, 108-115. [CrossRef]

5. Shore, F.M.; Morakabati, M.; Abbasi, S.M.; Momeni, A. Hot deformation behavior of incoloy 901 through hot tensile testing. J. Mater. Eng. Perform. 2014, 23, 1424-1433. [CrossRef]

6. Deng, J.; Lin, Y.C.; Li, S.-S.; Chen, J.; Ding, Y. Hot tensile deformation and fracture behaviors of AZ31 magnesium alloy. Mater. Des. 2013, 49, 209-219. [CrossRef]

7. Bai, G.; Li, J.; Hu, R.; Tang, Z.; Xue, X.; Fu, H. Effect of temperature on tensile behavior of Ni-Cr-W based superalloy. Mater. Sci. Eng. A 2011, 528, 1974-1978. [CrossRef]

8. Novella, M.F.; Ghiotti, A.; Bruschi, S.; Bariani, P.F. Ductile damage modeling at elevated temperature applied to the cross wedge rolling of AA6082-T6 bars. J. Mater. Process. Technol. 2015, 222, 259-267. [CrossRef]

9. Wang, L.; Yu, H.; Lee, Y.-S.; Kim, M.-S.; Kim, H.-W. Effect of microstructure on hot tensile deformation behavior of 7075 alloy sheet fabricated by twin roll casting. Mater. Sci. Eng. A 2016, 652, 221-230. [CrossRef]

10. Ghavam, M.H.; Morakabati, M.; Abbasi, S.M.; Badri, H. Flow behavior modeling of IMI834 titanium alloy during hot tensile deformation. Trans. Nonferr. Met. Soc. China 2015, 25, 748-758. [CrossRef]

11. Liu, G.; Wang, K.; He, B.; Huang, M.; Yuan, S. Mechanism of saturated flow stress during hot tensile deformation of a TA15 Ti alloy. Mater. Des. 2015, 86, 146-151. [CrossRef]

12. Cao, F.; Xia, F.; Xue, G. Hot tensile deformation behavior and microstructural evolution of a Mg-9.3Li-1.79Al-1.61Zn alloy. Mater. Des. 2016, 92, 44-57. [CrossRef]

13. Zhou, M.; Lin, Y.C.; Deng, J.; Jiang, Y.Q. Hot tensile deformation behaviors and constitutive model of an Al-Zn-Mg-Cu alloy. Mater. Des. 2014, 59, 141-150. [CrossRef]

14. Ashok, K.; Maruthupandian, K.; Kumar, K.G.; Vishal, C.S. Micro-mechanical behaviour of AA2014 alloy during hot tensile testing. Trans. Indian Inst. Met. 2015, 68, 19-24. [CrossRef]

15. Lv, Y. Influence of laser surface melting on the micropitting performance of $35 \mathrm{CrMo}$ structural steel gears. Mater. Sci. Eng. A 2013, 564, 1-7. [CrossRef] 
16. Zhang, J.W.; Lu, L.T.; Shiozawa, K.; Zhou, W.N.; Zhang, W.H. Effect of nitrocarburizing and post-oxidation on fatigue behavior of 35CrMo alloy steel in very high cycle fatigue regime. Int. J. Fatigue 2011, 33, 880-886. [CrossRef]

17. Zhang, J.; Lu, L.; Cui, G.; Shen, X.; Yi, H.; Zhang, W. Effect of process temperature on the microstructure and properties of gas oxynitrocarburized 35CrMo alloy steel. Mater. Des. 2010, 31, 2654-2658. [CrossRef]

18. Zhang, B.; Zhang, H.; Ruan, X. Dynamic recrystallization behavior of 35CrMo structural steel. J. Cent. South Univ. Technol. 2003, 10, 13-19. [CrossRef]

19. Xiao, Z.; Huang, Y.; Liu, Y. Plastic deformation behavior and processing maps of 35CrMo steel. J. Mater. Eng. Perform. 2016, 25, 1219-1227. [CrossRef]

20. Williams, B.P. The effect of nonuniformities of stress at the neck of a tension specimen. In Studies in Large Plastic Flow and Fracture; Harvard University Press: Cambridge, MA, USA, 1964; pp. 9-37.

21. Lin, Y.C.; Deng, J.; Jiang, Y.; Wen, D.; Liu, G. Hot tensile deformation behaviors and fracture characteristics of a typical Ni-based superalloy. Mater. Des. 2014, 55, 949-957. [CrossRef]

22. Hutchinson, J.W.; Neale, K.W. Influence of strain-rate sensitivity on necking under uniaxial tension. Acta Metall. 1977, 25, 839-846. [CrossRef]

23. Li, D.; Wei, Y.; Liu, C.; Hou, L. Hot deformation behaviors of Fe-30Mn-3Si-3Al twip steel during compression at elevated temperature and strain rate. Steel Res. Int. 2013, 84, 740-750. [CrossRef]

24. Torabinejad, V.; ZareiHanzaki, A.; Moemeni, S. An analysis to the kinetics of austenite recrystallization in Fe-30Mn-5Al steel. Mater. Manuf. Process. 2012, 28, 36-41. [CrossRef]

25. Sugandhi, R.; Warrier, M.; Chaturvedi, S. Identification of best fit parameters of void nucleation and growth model using particle swarm technique. Appl. Soft Comput. 2015, 35, 113-122. [CrossRef]

26. Zhang, H.; Zhang, K.; Jiang, S.; Zhou, H.; Zhao, C.; Yang, X. Dynamic recrystallization behavior of a $\gamma^{\prime}$-hardened nickel-based superalloy during hot deformation. J. Alloy. Compd. 2015, 623, 374-385. [CrossRef]

27. Sun, Y.; Xie, J.; Hao, S.; Wang, A.; Liu, P.; Li, M. Dynamic recrystallization model of 30\%SiCp/Al composite. J. Alloy. Compd. 2015, 649, 865-871. [CrossRef]

28. Quan, G.Z.; Luo, G.C.; Liang, J.T.; Wu, D.S.; Mao, A.; Liu, Q. Modelling for the dynamic recrystallization evolution of Ti-6Al-4V alloy in two-phase temperature range and a wide strain rate range. Comput. Mater. Sci. 2015, 97, 136-147. [CrossRef]

(C) 2016 by the authors; licensee MDPI, Basel, Switzerland. This article is an open access article distributed under the terms and conditions of the Creative Commons Attribution (CC-BY) license (http:/ / creativecommons.org/licenses/by/4.0/). 